\title{
Experimental Evidence on the Thermal Performance of Opaque Surfaces in Mediterranean Climate
} \author{
V. Franzitta ${ }^{1, a}$, A Milone $^{1, b}$, D. Milone
A.Viola ${ }^{1, \mathrm{c}}, \mathrm{S}$. \\ ${ }^{1}$ DEIM-Dipartimento Di Energia, Ingegneria Dell'informazione, E Modelli Matematici, University of \\ Palermo, Palermo 90128, Italy \\ ${ }^{2}$ Facoltà di Architettura Università degli Studi Palermo, Viale delle Scienze 14, Palermo 90128, Italy \\ a franzitta@dream.unipa.it, bangelo.milone@unipa.it, c daniele.milone@unipa.it, \\ d salvatore.pitruzzella@unipa.it, marco.trapanese@unipa.it ${ }^{\mathrm{e}}$, alessia.viola@unipa.it, ${ }^{\mathrm{f}}$.
}

Keywords: Thermal insulation, Energy performance of building, Opaque surfaces, Thermophysical of involucr.

\begin{abstract}
The thermal insulation of buildings, intended as wrap feature which determines the dispersion of heat, the reference parameter is necessary to contain the thermal losses during the winter season. The transmittance of the opaque components, used as an indicator of the energy quality of a casing, together with the overall coefficient of dispersion, represents a proper descriptor of the behavior during the heating season.

However, if a strong insulation in winter conditions brings only positive effects, the same cannot be said for the summer conditions. A high value of the insulation in the casing is convenient only when the gains free, either in the form of solar contribution that of endogenous heat, are controlled and restricted. From the national transposition of the 2002/91/CE legislation up to the 2010/31/EU on the energy performance of buildings, performance values are set very restrictive transmittance of opaque surfaces that both of those transparent to the new buildings. The same does not happen for the thermophysical characteristics able to implement strategies for the control of solar radiation during the summer period, the fluctuations in external temperatures during the summer period.

This article shows some experimental evidence of the effects on transmission rate and density of the opaque elements of the buildings carried out on a case study of a representative building of climate-Mediterranean summer: The study verify the results produced by increased insulation of the building envelope on energy performance of buildings during the summer through indicators such as temperature and energy consumption to maintain the same constant with respect to the prescribed values.
\end{abstract}

\section{Introduction}

In Italy, starting from the enactment of Law no. 311 of 2006 concerning the implementations of Directive 2002/91/CE on the energy performance of buildings, now partially modified by the transposition of the strictest directives contained in 2010/31/EU, are prescribed as mandatory, some values of maximum transmittance building components both opaque and transparent, part of both new buildings that existing buildings undergoing renovation.

These requirements, impose increasingly stringent $U$-values as a function of climate zone, but do not take into account, if not for the bland of the obligation for the climatic zones with high average daily temperatures in the summer of surface mass in excess of $230 \mathrm{~kg} / \mathrm{m} 2$ of the walls [1].

Alternatively, it is possible, according to the same rule, use different techniques and materials, so even with structures with surface mass less, provided they yield the same positive effects that would be obtained with this value. In particular, with regard to the damping and the phase shift of the thermal wave, which allow to contain the oscillations of the temperature of the environments in function of the solar radiation. 
It is clear that the legislation seeks to achieve, for the purpose of reducing energy consumption, only the reduction of leakage during the winter and put a lower limit to the mass surface does not guarantee the achievement of adequate performance summer

Methodology. Through the use of simulation software in dynamic conditions, we evaluated the energy performance of opaque structures to close a multi-storey residential building envelope and calculated according to the profile due to the climate zone " $\mathrm{C}$ " according to the classification of the Italian territory with a value of 1374 degree days .

Figure 1 shows both the profile of the average monthly temperatures daily, the monthly average of the daily temperature of the locality used for the calculation. In Figure 2 is shown a diagram of the various levels of the building with the differentiation of the type stratigraphic of the walls facing towards the North and South, while Figure 3 shows the details of stratigraphic walls, whose characteristics are reported in Tables 1 and 2 . Figure 4 shows the comparison of the thermal lag of the two walls in summer conditions, according to the climate data and the hottest day of the summer season with higher radiation.

Through the direct comparison of energy consumption distinguished between the heating season and the cooling, highlights the most energy efficient solutions [2].

The wall elements of vertical closure is not limited simply to be in the range of maximum transmittance for the climate zone of reference, but have been adopted stratigraphic compositions so as to accentuate the passive behavior of the building envelope [3].

For the building was simulated the amount of energy required in the various configurations of the vertical closing differentiating the winter season than summer.

The simulation of the energy needs provided for the setting of the set point temperature indoors Ta $\left[{ }^{\circ} \mathrm{C}\right]$ respectively at $20^{\circ} \mathrm{C}$ for winter and $26^{\circ} \mathrm{C}$ for the summer season, taking into account the needs and dispersions, both for transmission that for ventilation with an air exchange standard of $0.33 \mathrm{vol} /$ $\mathrm{h}[4-5]$.
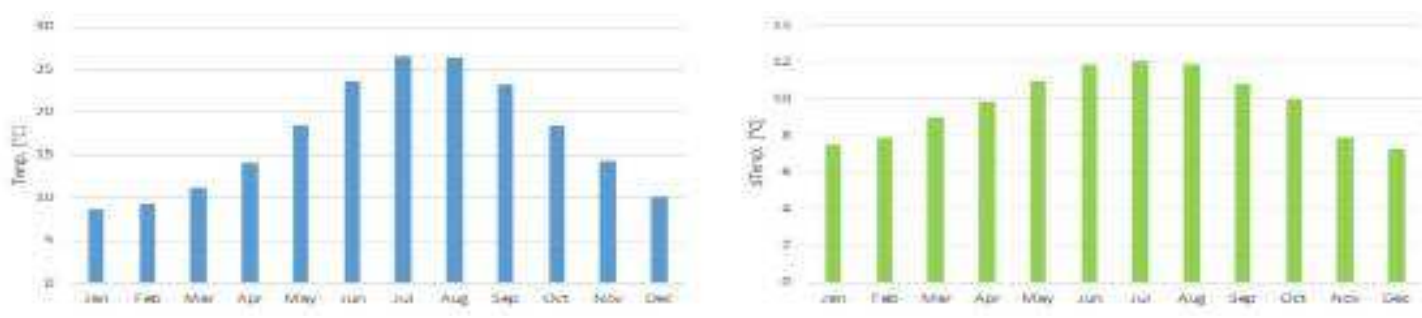

Figure 1. Climatic profile
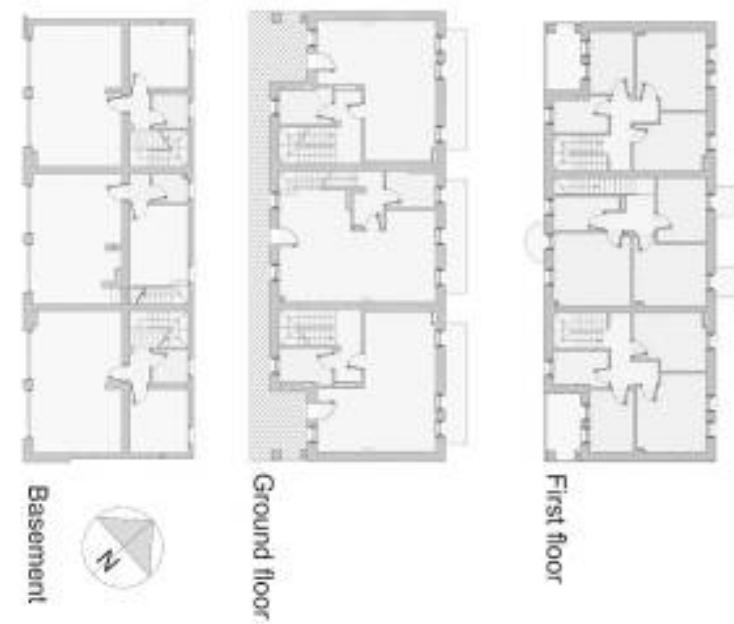

Figure 2. Building scheme simulated 


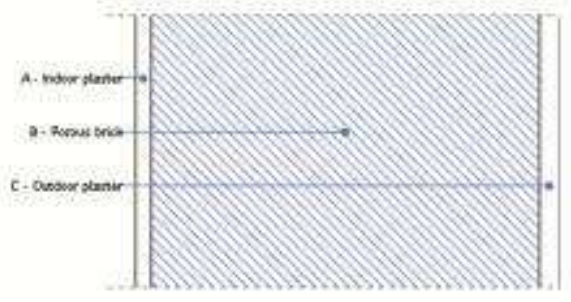

Wall $\alpha \mathrm{Ax}$

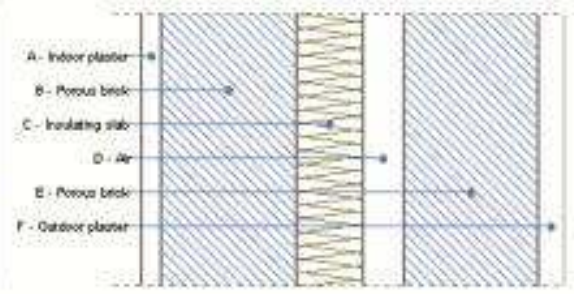

Wall $* \mathrm{~B}$ *

Figure 3. Wall stratigraphy

Table 1. Stratigraphic characteristics of the walls.

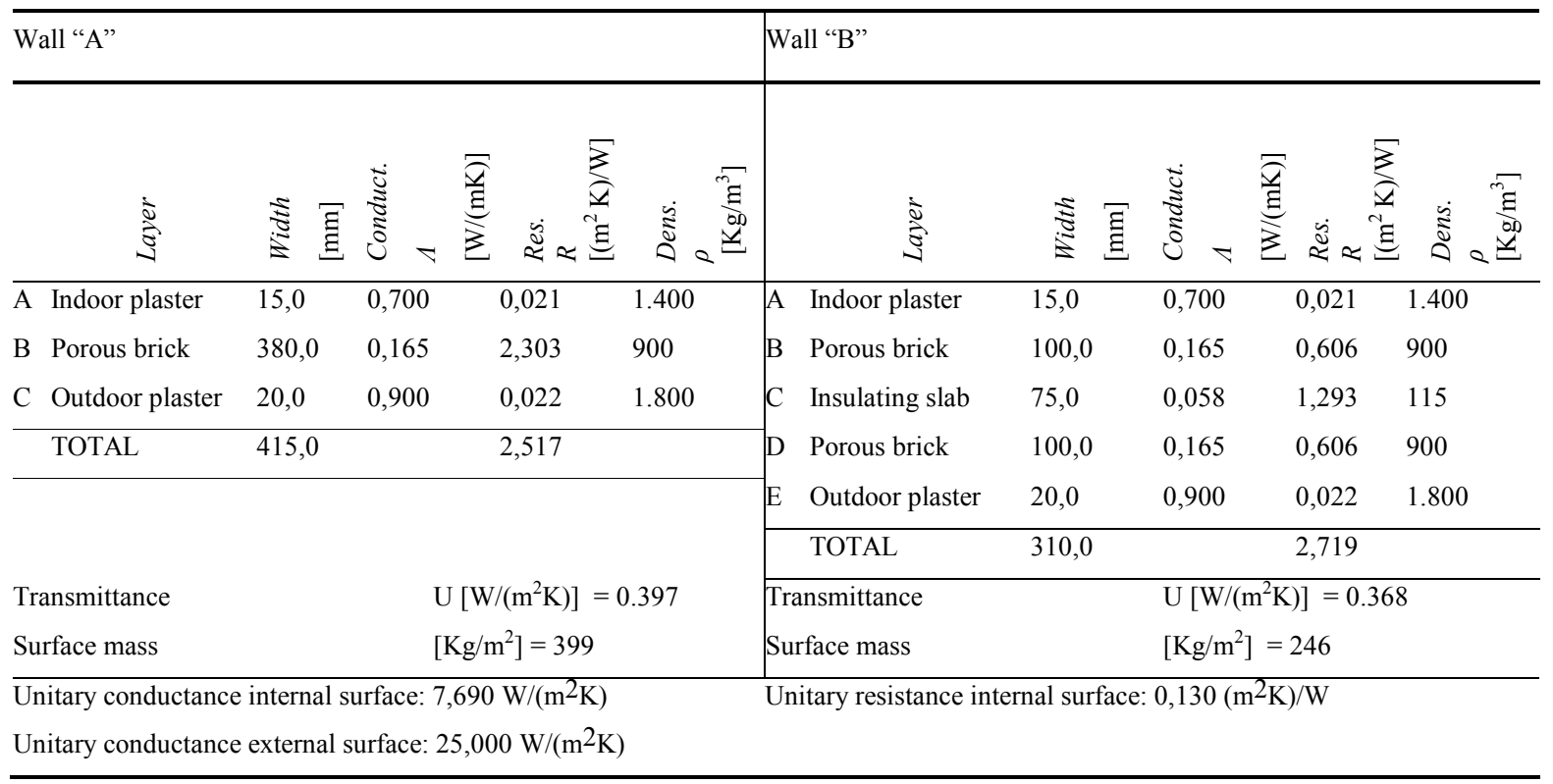

Table 2. Thermophysical parameters of the dynamic walls

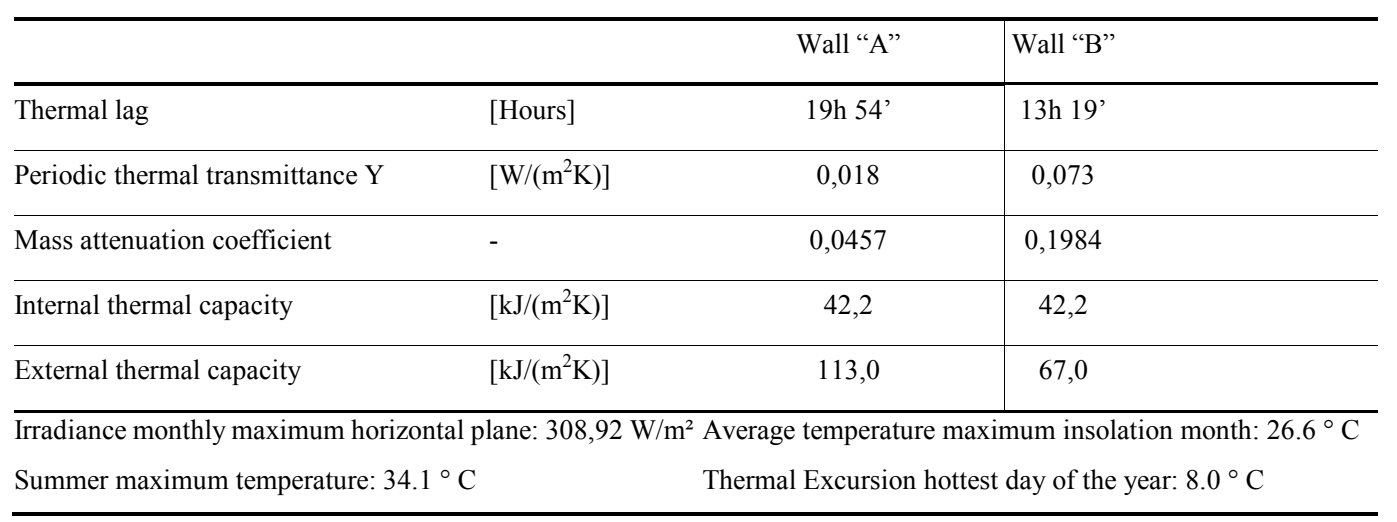

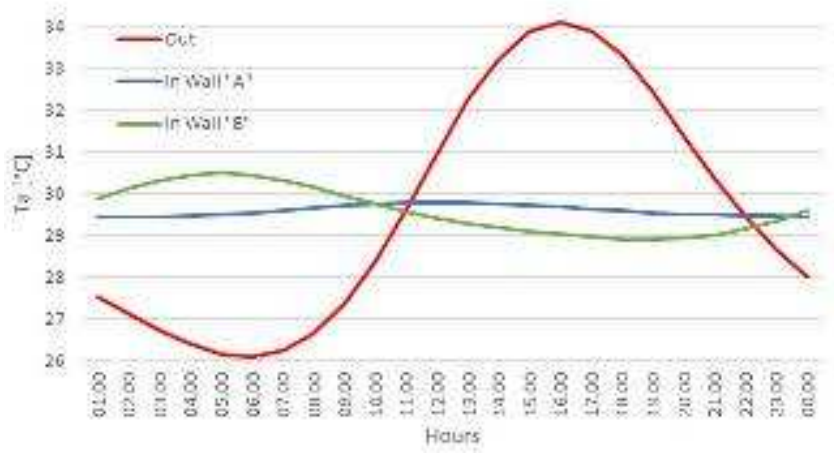

Figure 4. Thermal lag of the two types of walls hottest day of the summer season 
Results. The simulations, conducted just under dynamic conditions in order to evaluate the temperature fluctuations, especially during the cooling season, show a different behavior between the two seasons differentiating performance as a function of the stratigraphy of the closures vertical opaque.[6-8]

In this way are clearly emerging energy relations that are established between the components of the building and it was possible to observe how the mutual influences may affect the global heat balance.

The energy requirements on a monthly basis for each configuration of closures opaque is shown in figure 5 below, while in figure 6 is reported in the annual evaluation for the two configurations.

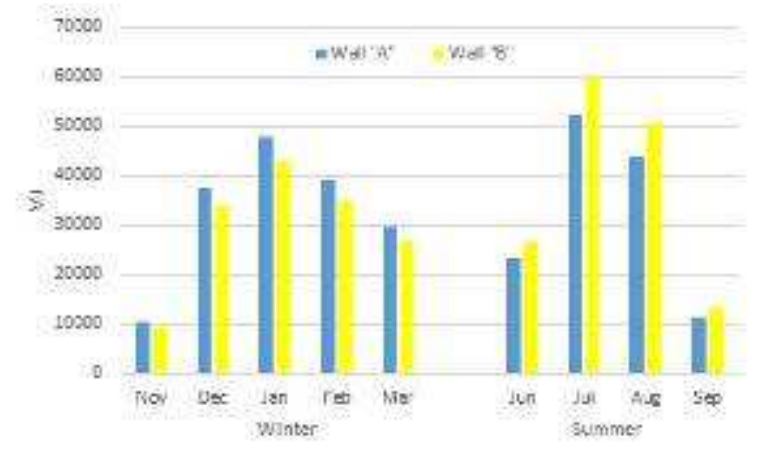

Figure 5. Energy on monthly basis for the two configurations

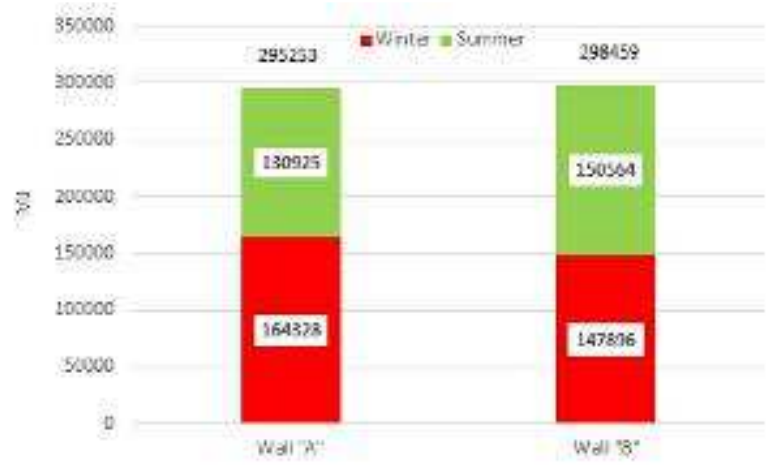

Figure 6. Energy on a seasonal basis and cumulative for the two configurations

In the configuration Wall "A" which provides a transmittance $\mathrm{U}=0.397 \mathrm{~W} /(\mathrm{m} 2 \mathrm{~K})$ and a surface mass $=399 \mathrm{~kg} / \mathrm{m} 2$, we consumption during the winter season of $164328 \mathrm{MJ}$, MJ 147896 against the wall configuration "B", which provides a transmittance $U=0.368 \mathrm{~W} /(\mathrm{m} 2 \mathrm{~K})$ and a surface mass $=246$ $\mathrm{kg} / \mathrm{m} 2$. In this season, the gap between consumption in the two configurations is $11.12 \%$.

In the summer season, consumption of $130925 \mathrm{MJ}$ for the wall configuration "A" and $150564 \mathrm{MJ}$ for configuring wall "B"[9-10]. The difference in consumption between the two configuration is of $15.01 \%$.

In terms of annual consumption, the wall configuration "A" consumes $295253 \mathrm{MJ}$ against the wal 298459 MJ configuration "B" with a gap of just $1.08 \%$.

The wall with a value of transmittance $\mathrm{U}[\mathrm{W} /(\mathrm{m} 2 \mathrm{~K})]$ but with a slightly higher value than thermal lag of $6 \mathrm{~h} 35^{\prime}$ demonstrates its ability to reduce the heat load in summer.

Figure 7 is a graph of comparison between the seasonal distribution in percentage of consumption in the two configurations.

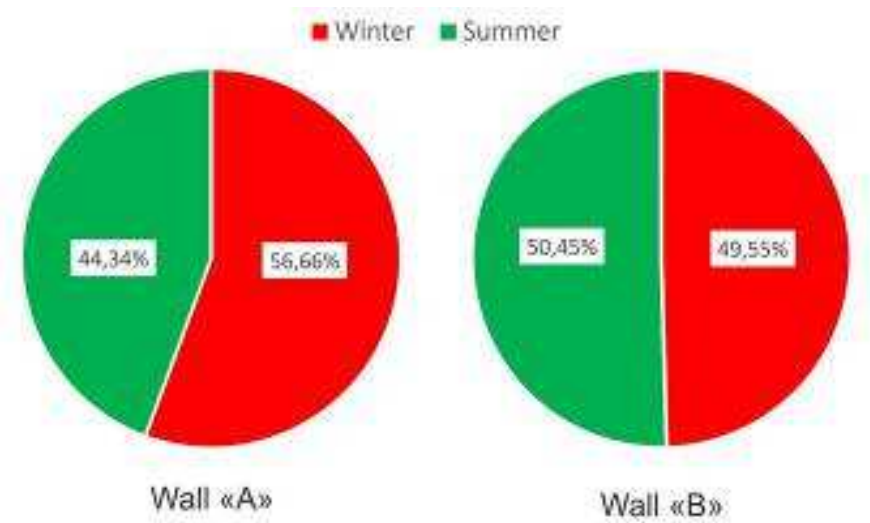

Figure 7. Seasonal distribution of consumption for the two configurations.

Seen the paltry difference between the two configurations on a yearly basis, Whereas the increased performance in a season correspond to minor in the other, it is appropriate to multiply the 
consumption values obtained in the two seasons for the conversion factor to primary energy, the energy carrier used in heating and cooling and expected returns for its plant.

\section{Conclusions.}

Take the transmittance as the sole indicator lets you perform energy analysis simplified, that is under steady state, for which there are insufficient climate data highly aggregated on a monthly or even seasonal.

The closures opaque with a consistent mass accumulate and release heat in a complex way, not only dampens the peak temperature of the outside, but defer over time: it is the so-called "thermal inertia", which generates very significant impact on the energy performance overall, both in summer and in winter.

The adoption of passive cooling strategies based on such phenomena requires to conduct an analysis under dynamic conditions, setting a time scale that is very small, of the order of hours, this allows us to consider with the right weight factors like hiking thermal and day-night variation of solar radiation during the day.

\section{References}

[1] D. Milone, S. Pitruzzella, V. Franzitta, A.Viola, M. Trapanese. Energy savings through integration of the illumination natural and artificial, using a system of automatic dimming: Case. Applied Mechanics and Materials, Vol. 372 (2013) pp 253-258

[2] A. Galatioto, S. Pitruzzella, G. Scaccianoce,D. Milone. Regional policies for sustainability in the Mediterranean countries: the role of a proper HVAC system maintenance in museums. Applied Mechanics and Materials Vols. 316-317 (2013) pp 1147-1151.

[3] V. Franzitta, A. Milone, D. Milone, M. Trapanese, A. Viola. A case study to the Evaluation of Global Environmental Quality, concerning thermal, acoustic and atmospheric conditions of urban areas. Advanced Materials Research Vol. 726 (2013) pp 1068-1072.

[4] V. Franzitta, A.Viola, M. Trapanese, Daniele Milone. A procedure to evaluate the indoor global quality by a sub objective-objective procedure. Advanced Materials Research Vols. 734-737 (2013) pp 3065-3070,.

[5] V. Franzitta, D. Milone, M. Trapanese, A. Viola, V. Di Dio, S. Pitruzzella. Energy and Economic Comparison of different conditioning system among traditional and eco-sustainable building. Applied Mechanics and Materials, Vol. 394 (2013), pp 289-295

[6] A. Galatioto, A.Milone, D.Milone, S. Pitruzzella. Proceedings of ICAE 201. Perugia, Italy, 2011. Assessment of the renewable energy production in an historical building for a touristic intended use: a technical-economic feasibility study. . Proceedings of ICAE 201. Perugia, Italy, 2011.

[7] A. Milone, D. Milone, S. Pitruzzella. Asset rating: disagreement between the results obtained from software for energy certification. 11th International Building Performance Simulation Association Conference and Exhibition Building Simulation 2009, pp. 569-575; University of Strathclyde (GBR), Glasgow 27-30 Luglio 2009.

[8] A. Milone, D. Milone, S. Pitruzzella. The energy certification of buildings through the dynamic simulation of variable consumption. Proceedings of renewable energy congress X, Glasgow, Scotland, 19-25 july 2008. ISBN: 978-008-056-8973

[9] V. Baiamonte, A. Milone, D. Milone, S. Pitruzzella. The use of transparent insulating materials in low energy consumption buildings, through the study of thermic and optical behaviour. Proceedings of IX WORLD RENEWABLE ENERGY CONGRESS. Florence 19-25 august 2006. ISBN: 0-08-045056-3

[10] M. Trapanese, V. Franzitta, , A Viola. The Jiles Atherton Model for Description Of Hysteresis in Lithium Battery. Conference Proceedings - IEEE Applied Power Electronics Conference and Exposition - APEC 2013- Long Beach,(CA), March 2013-978-1-4673-4355-8, pp 2773-2775. 


\section{Energy Development}

10.4028/www.scientific.net/AMR.860-863

Experimental Evidence on the Thermal Performance of Opaque Surfaces in Mediterranean Climate 10.4028/www.scientific.net/AMR.860-863.1227 